\title{
Manipulating Dislocations Using Electric Field to Repair Embrittlement Damage
}

\author{
Xin BA, ${ }^{1)}$ Mengcheng $\mathrm{ZHOU},{ }^{11}$ Xinfang $\mathrm{ZHANG}^{1 / *}$ and Hui WANG ${ }^{21}$ \\ 1) State Key Laboratory of Advance Metallurgy, School of Metallurgical and Ecological Engineering, University of Science and \\ Technology Beijing, Beijing, 100083 P.R. China. \\ 2) Science and Technology on Reactor Fuel and Materials Laboratory, Nuclear Power Institute of China, Chengdu, 610041 \\ P.R. China.
}

(Received on September 13, 2019; accepted on January 7, 2020)

\begin{abstract}
Dislocation defects induced by neutron irradiation can degrade the mechanical properties of reactor pressure vessel steel; although the properties can be restored by annealing, this treatment is energy- and time-intensive. A fast and energy-efficient method of decreasing the dislocation density is urgently needed. In this study, electric pulse treatment was applied to damaged A508-3 steel to remove the dislocation defects quickly. The pulsed electric current reduced the dislocation density in a brittle sample and improved the impact toughness. After electric pulse treatment, the ductile-brittle transition temperature was $11.8^{\circ} \mathrm{C}$ lower. Calculations revealed that the higher temperature around the dislocations and the electron wind force under the electric field decreased the activation energy of dislocation motion, causing the dislocations to move more easily. The dislocation defects can be annihilated as they move, decreasing the dislocation density.
\end{abstract}

KEY WORDS: A508-3 steel; irradiation embrittlement; dislocation density; pulsed electric current.

\section{Introduction}

A dislocation defect is an irregularity in the arrangement of one or more columns of atoms in a cubic crystal; the concept was first proposed by Taylor to explain why slipping occurs over a limited region but not over all the atoms in the slip plane. ${ }^{1)}$ Dislocation strengthening is currently one of the most effective strengthening methods. However, a high dislocation density will compromise the ductility and toughness. ${ }^{2-4)}$ The mechanical properties of a reactor pressure vessel (RPV) will deteriorate sharply because of the increase in dislocation density after the high-energy neutron beam irradiation in service. ${ }^{5-7)}$ Lin et al. tested the Charpy impact energy of A508-3 steel before and after neutron irradiation and found that $T_{41 \mathrm{~J}}$ increased $68^{\circ} \mathrm{C} .^{5)}$ Marini et al. found that the yield stress of 16MND5 increased by more than $14 \%$ after irradiation, and the ultimate tensile stress increased by more than $12 \%{ }^{8}{ }^{8}$ In Pawel's study, the fracture toughness of various materials all decreased after irradiation to $3 \mathrm{dpa} .{ }^{9)}$ It was shown that the dislocation density in thin foils of RPV steel weld increased after years of neutron irradiation, ${ }^{10)}$ and $\mathrm{Cu}, \mathrm{Mn}, \mathrm{Ni}$, and $\mathrm{Si}$ atoms were enriched at dislocations, ${ }^{11)}$ which resulted in $\mathrm{Cu}-, \mathrm{Mn}-$, and $\mathrm{Ni}$-rich clusters and decreased the toughness. Long-duration ex situ annealing treatment can reportedly reduce the matrix defect damage in RPV steel. ${ }^{10-12)}$ Miller et al. ${ }^{13)}$ annealed RPV steel with irradiation embrittlement damage at $460^{\circ} \mathrm{C}$

\footnotetext{
* Corresponding author: E-mail: xfzhang@ustb.edu.cn DOI: https://doi.org/10.2355/isijinternational.ISIJINT-2019-583
}

for $168 \mathrm{~h}$ and found that the toughness was restored after annealing. Moreover, the Army SM-1A RPV in the United States $^{14)}$ and Loviisa FPV in the Soviet Union, ${ }^{15}$ which exhibited embrittlement damage after service, were repaired by annealing, although the reasons for the recovery were not given. The results showed that after annealing, the ductile-brittle transition temperature (DBTT) of the brittle samples recovered from $25 \%$ to $100 \%$. However, all of these annealing treatments required a high temperature of $360^{\circ} \mathrm{C}$ to $480^{\circ} \mathrm{C}$ and more than $168 \mathrm{~h}$, so a large amount of energy was needed to reduce the dislocation defects. In addition, the use of annealing in production is limited because the embrittlement damage of RPV can be repaired only by putting the heat source inside it, as the RPV cannot be moved. The premise of the annealing recovery is that the reactor cores need to be carried out of the RPV, and the risk and caseload of the carrying are worth considering. Therefore, an energy-saving method for in situ repair of RPVs with irradiation embrittlement damage is needed.

A pulsed electric current has been studied as an instantaneous high-energy input method for materials. An electric pulse is known to affect the microstructural evolution, ${ }^{16,17)}$ recovery and recrystallization, ${ }^{18)}$ phase transformation, ${ }^{19}$ texture evolution, ${ }^{20)}$ and diffusion. ${ }^{21,22)}$ In a study of the dislocations and mechanical properties, Kim et al. ${ }^{23)}$ treated Al 5052-H32 by a pulsed electric current under uniaxial tension and found that the pulsed current softened the flow stress and increased the elongation dramatically. Kim et al. suggested that an electric current can induce annealing as a distinct role from Joule heating. Tang et al. ${ }^{24)}$ applied elec- 
tric current to SUS316 steel after tensile fatigue tests and observed that the dislocation density was much lower than that when the electric current was not applied. Liu et al. ${ }^{25)}$ treated AZ31 magnesium alloy with a pulsed current and discovered that the pulsed current decreased the dislocation density much more rapidly than annealing did. Research showed that an electric current reduced the dislocation density and promoted the plasticity of materials. ${ }^{23-26)}$ However, restoration of the toughness of brittle metals using pulsebased processing has not been reported, although the effect of annealing treatment has been widely studie. ${ }^{27,28)}$

In this study, brittle A508-3 steel, a type of RPV steel, was treated by a pulsed electric current. It was found that the toughness of the brittle A508-3 steel was recovered because the dislocation defects were reduced by electropulsing. In addition, the lower activation energy of dislocation movement under the electric field and the interaction between electrons and dislocations were explained in terms of electroplastic theory and formulas derived from solidstate physics.

\section{Material and Methods}

A508-3 steel containing $0.20 \mathrm{C}, 1.30 \mathrm{Mn}, 0.14 \mathrm{Cr}, 0.90$ $\mathrm{Ni}$, and $0.039 \mathrm{Cu}$ was used in this study. Since the neutron irradiation experiment requires a long time (several years) and the irradiated sample is then radioactive, the neutron irradiation experiment is replaced by aging the sample at $400^{\circ} \mathrm{C}$ for $1000 \mathrm{~h}$ to make it brittle, as reported in the study. ${ }^{29)}$ The brittle sample was found to have more dislocation defects and lower toughness. It was cut to $30 \mathrm{~mm} \times$ $10 \mathrm{~mm} \times 1 \mathrm{~mm}$ for optical microscopy $(\mathrm{OM})$, transmission electron microscopy (TEM), and X-ray diffraction (XRD) observations, tensile tests, and Charpy V-notch impact tests. The brittle A508-3 samples were treated by a pulsed electric current using the instrumental setup illustrated in Fig. 1(a), and the TEM sample was cut from the middle of the pulsed sample. The samples for the microstructural analysis and mechanical tests were treated by electric pulses for $30 \mathrm{~min}$ at a frequency of $500 \mathrm{~Hz}$, pulse duration of $20 \mu \mathrm{s}$, and current density of $4 \mathrm{~A} / \mathrm{mm}^{2}$. To characterize the microstructure, the samples were ground and mechanically polished. The polished surfaces were etched with a $10 \%$ Nital solution. Image $\mathrm{J}$ was used to calculate the grain size of the brittle and pulsed samples. Furthermore, XRD analysis was used to calculate the dislocation density using a Bruker D8 Advance X-ray diffractometer with $\mathrm{Cu} \mathrm{K} \alpha$ radiation $(\lambda=$ $0.15406 \mathrm{~nm}$ ) operating at $40 \mathrm{kV}$ in step scanning mode at a scan speed of $0.02^{\circ} \mathrm{s}$. A scan range of $35^{\circ}$ to $150^{\circ}$ was chosen to cover all the diffraction peaks of bainite ferrite. To determine the strength and toughness of the A508-3 steel, a tensile test and Charpy V-notch impact test were performed. The tensile test samples were cut as shown in Fig. 1(b). According to ASTM A370 and E23, the Charpy $\mathrm{V}$-notch impact samples were prepared as cuboids $55 \mathrm{~mm} \times$ $10 \mathrm{~mm} \times 5 \mathrm{~mm}$ in size, and the depth of the V-notch was $2 \mathrm{~mm}$ (Fig. 1(c)). The Boltzmann function was used to fit the impact experiment data and obtain the Charpy impact absorbed energy curve of the A508-3 steel. According to ASTM A370, the DBTT is the temperature at which the sample's impact absorbed energy was half the upper shelf (a)

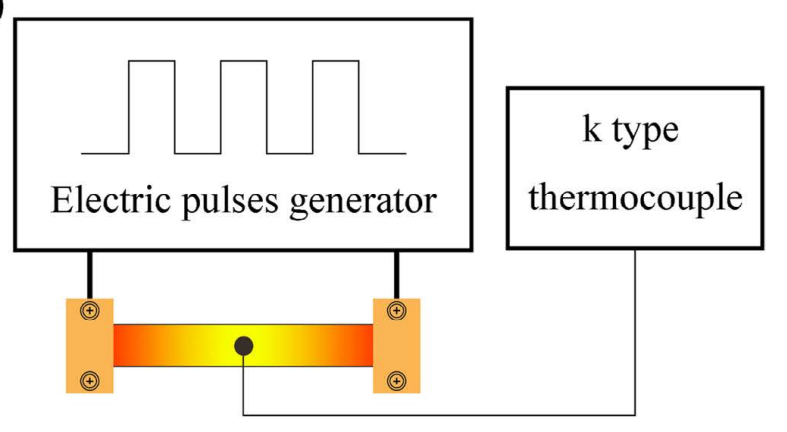

(b)

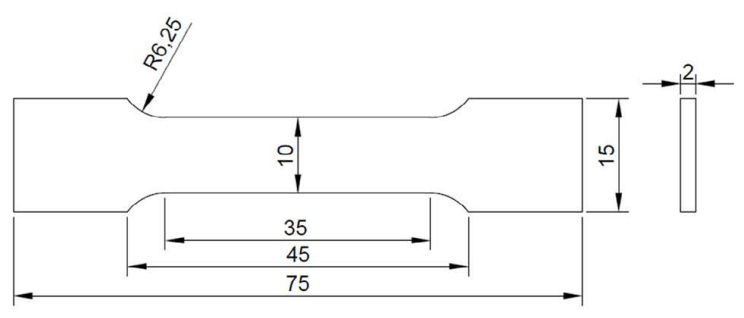

(c)

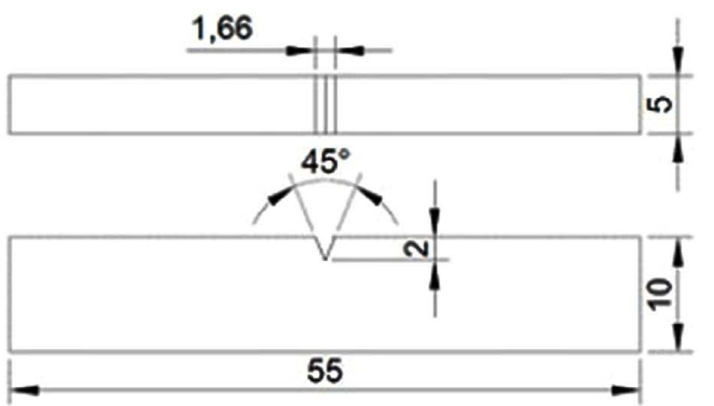

Fig. 1. a) Diagram of instrumental set-up for electropulsing, b) tensile test sample, c) Charpy impact sample. (Online version in color.)

energy. The brittle samples were treated by the pulsed current, and then the tensile and impact tests were conducted. The samples were cut to $1 \mathrm{~mm} \times 1 \mathrm{~mm} \times 50 \mathrm{~mm}$ to measure the electrical resistivity.

\section{Results and Discussion}

The microstructure of the as-received sample (Fig. 2(a)), brittle sample (Fig. 2(b)), and electric-pulse-treated sample (Fig. 2(c)) was lath bainite. The electric current treatment did not change the microstructure of the material. The average diameter of the original austenite grains ranged from 10 to $20 \mu \mathrm{m}$, as shown in Fig. 2(d), indicating that electric pulse treatment did not change the grain size of the material, which was important for the subsequent XRD analysis.

For each diffraction vector, dislocations with a Burgers vector $b$ that fulfills the condition $g \cdot b=0$ become invisible, ${ }^{30)}$ which affects the estimated dislocation density. To weaken the effect of $g \cdot b$ invisibility, the dislocations of the samples were observed with different diffraction vectors. TEM graphs with different diffraction vectors $[B=<001>$ (Fig. 3(a)), $B=<011>$ (Fig. 3(b)), and $B=<111>$ (Fig. $3(\mathrm{c}))$ ] show that the dislocation density is low and the dislocations are discrete in the as-received sample. Figures 3(d), 3(e), and 3(f) show that the dislocation density is higher and there are many dislocation tangles in the brittle A508-3 steel. After treatment by electropulsing at $500 \mathrm{~Hz}, 20 \mu \mathrm{s}$, 

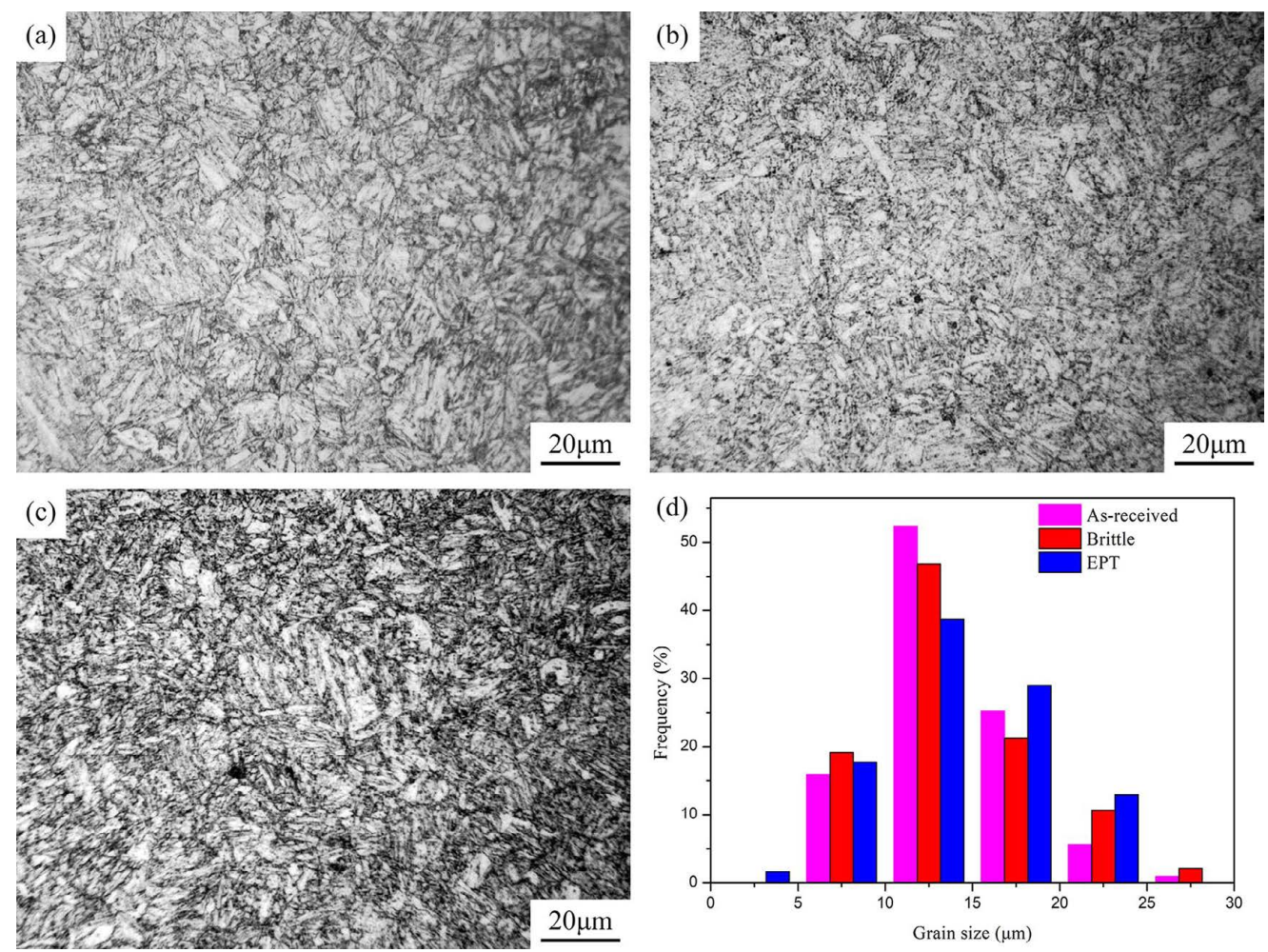

Fig. 2. Microstructure of various samples: a) as-received, b) brittle, and c) after electric pulse treatment $(500 \mathrm{~Hz}, 20 \mu \mathrm{s}$, $4 \mathrm{~A} / \mathrm{mm}^{2}, 30 \mathrm{~min}$ ); d) grain size distributions of the samples. EPT indicates electric pulse treatment. (Online version in color.)

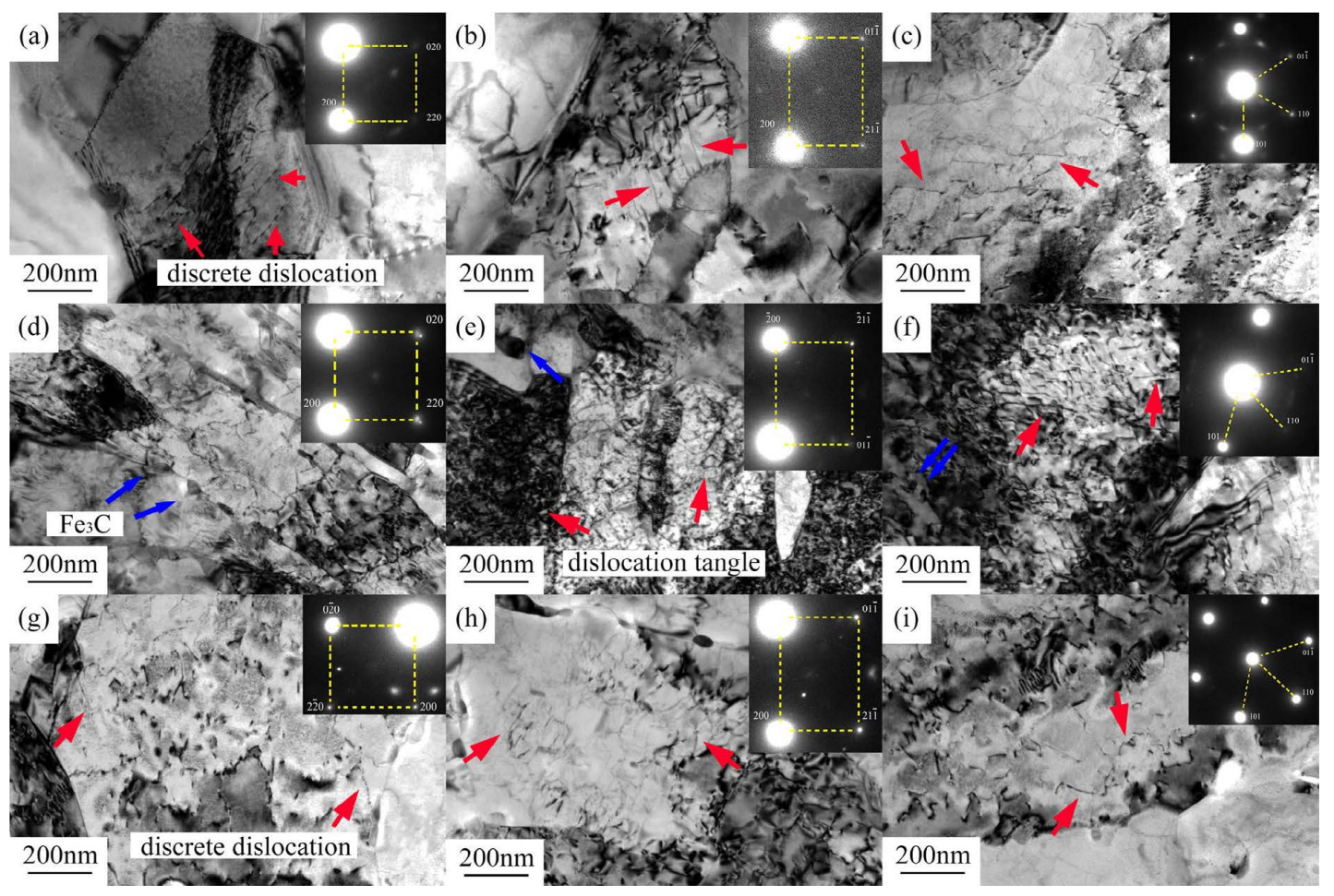

Fig. 3. Discrete dislocations in as-received sample for different diffraction vectors: a) $B=\langle 001\rangle$, b) $B=\langle 011\rangle$, c) $B=\langle 111>$; dislocation tangles in brittle sample for different diffraction vectors: d) $B=<001>$, e) $B=$ $<011>$,f) $B=<111>$; discrete dislocations in the brittle sample after electric pulse treatment $(500 \mathrm{~Hz}, 20 \mu \mathrm{s}$, $4 \mathrm{~A} / \mathrm{mm}^{2}, 30 \mathrm{~min}$ ) for different diffraction vectors: g) $B=\langle 001>$, h) $B=\langle 011>$, i) $B=<111>$. (The red arrows indicate the dislocation defects, and the blue arrows indicate $\mathrm{Fe}_{3} \mathrm{C}$ ). (Online version in color.)

and $4 \mathrm{~A} / \mathrm{mm}^{2}$ for $30 \mathrm{~min}$, the dislocation density decreased, and the dislocation tangles were dispersed (Figs. $3(\mathrm{~g}), 3(\mathrm{~h})$, and 3(i)). Thus, the dislocation defects were reduced by the pulsed electric current.

To quantify the difference in dislocation density before and after electropulsing, XRD analysis was performed. The 
diffraction peaks are known to become broader when the grain size changes or the lattice distortion increases in a crystal. ${ }^{31,32)}$ In this study, as mentioned above, the grain size was approximately $15 \pm 5 \mu \mathrm{m}$. Therefore, the broadening of the diffraction peaks is closely related to the increase in dislocation defects. Figure 4(a) shows the change in the full width at half-maximum (FWHM) of the samples. The FWHMs of all the diffraction peaks of the brittle A508-3 steel are clearly wider than those of the as-received sample. After treatment by electropulsing, the FWHMs of the sample dropped substantially and became essentially equal to those of the as-received sample.

Ungár et al. ${ }^{33-35)}$ optimized the traditional method [the Williamson-Hall (WH) method] of calculating the dislocation density using XRD and developed a more accurate method, the modified Williamson-Hall (MWH) method, as shown in Eq. (1).

$$
\Delta K=\frac{0.9}{D}+\left(\frac{\pi M^{2} b^{2}}{2}\right)^{\frac{1}{2}} \rho^{\frac{1}{2}} K \bar{C}^{\frac{1}{2}}+\mathrm{O}\left(K^{2} \bar{C}\right)
$$

where $\Delta K=2 \cos \theta \Delta \theta / \lambda, K=2 \sin \theta / \lambda, O$ indicates higherorder terms, $\rho$ is the dislocation density, and $2 \theta$ is the diffraction angle. When $\Delta K$ and $K \bar{C}^{\frac{1}{2}}$ are calculated for each diffraction peak, the relation between $\Delta K$ and $K \bar{C}^{\frac{1}{2}}$ is determined by the least square method, and the dislocation

(a)

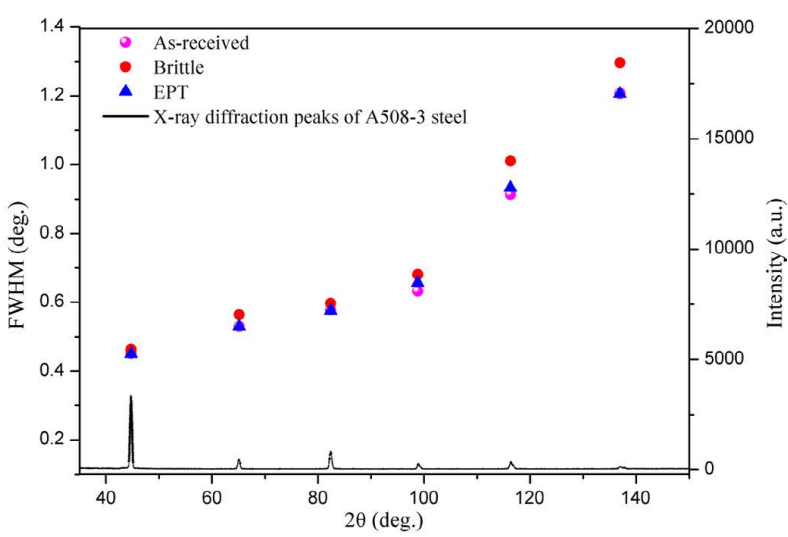

(b)

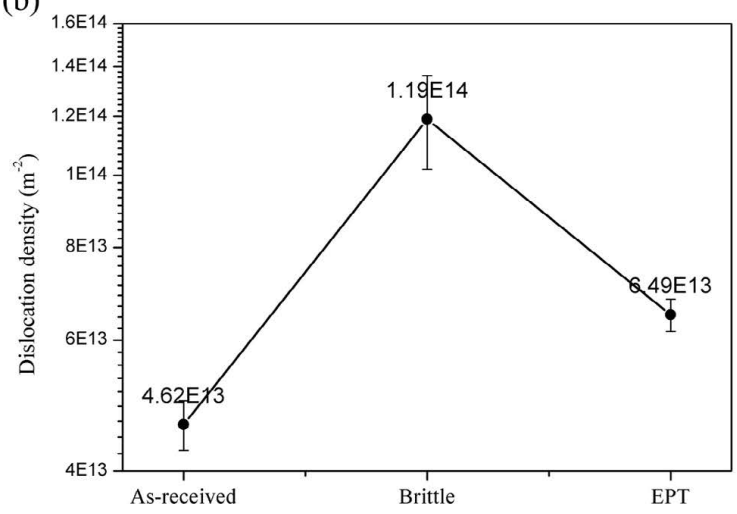

Fig. 4. a) Comparison of the FWHMs of all the peaks from $35^{\circ}$ to $150^{\circ}$ of the as-received, brittle, and electric-pulse-treated $\left(500 \mathrm{~Hz}, 20 \mu \mathrm{s}, 4 \mathrm{~A} / \mathrm{mm}^{2}, 30 \mathrm{~min}\right)$ samples. b) Dislocation density of the as-received, brittle, and electric-pulsetreated samples calculated by the MWH method. EPT indicated electric pulse treatment. (Online version in color.) density $\rho$ can be calculated as the slope. The dislocation densities of the as-received, brittle, and pulsed samples were calculated by the MWH method, and the result is shown in Fig. 4(b). The dislocation densities of the as-received and brittle samples were $4.62 \times 10^{13} \mathrm{~m}^{-2}$ and $1.16 \times 10^{14} \mathrm{~m}^{-2}$, respectively. Electric pulse treatment reduced the dislocation density by $45 \%$, to $6.49 \times 10^{13} \mathrm{~m}^{-2}$, which is close to that of the as-received sample.

The application of multi-pulse treatment and a direct current reportedly decreases the ultimate tensile strength and yield stress of austenite-martensite transformation-induced plasticity steel. ${ }^{36)}$ The pulsed electric current can also affect the tensile strength of A508-3 steel. Figure 5 presents the tensile curves of a brittle specimen obtained in pulsed and non-pulsed tensile tests. The tensile samples were treated by electric pulses $\left(500 \mathrm{~Hz}, 20 \mu \mathrm{s}, 4 \mathrm{~A} / \mathrm{mm}^{2}\right)$ for $30 \mathrm{~min}$. The result shows that the yield stress and tensile stress of the brittle sample increased by 106 and $108 \mathrm{MPa}$, respectively, compared to those of the as-received sample, and the elongation decreased sharply, from $17.6 \%$ to $15.0 \%$. The brittle sample had higher strength and lower plasticity than the as-received sample, demonstrating effects similar to those of neutron irradiation on RPV steel. ${ }^{37)}$ Furthermore, the crosssectional area of the as-received, brittle, and electric-pulsetreated samples after tensile testing is measured as shown in
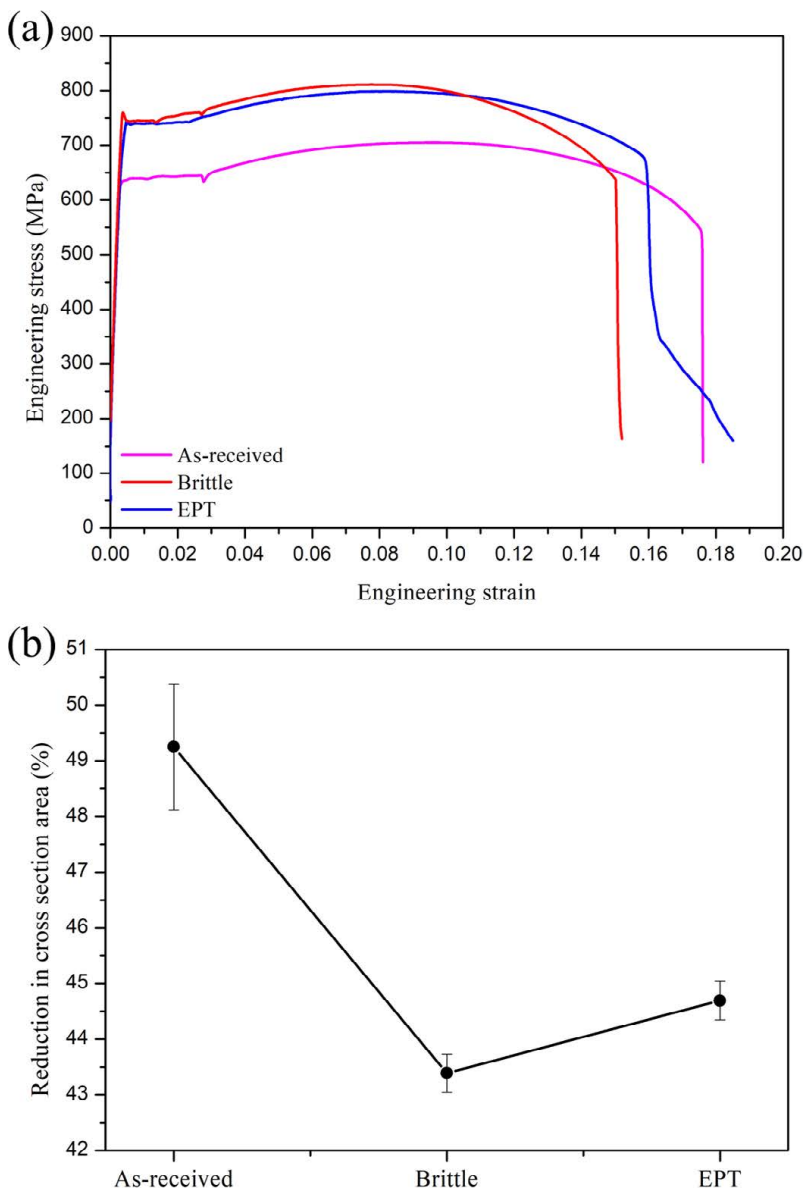

Fig. 5. a) Tensile curves of as-received, brittle, and electric-pulsetreated $\left(500 \mathrm{~Hz}, 20 \mu \mathrm{s}, 4 \mathrm{~A} / \mathrm{mm}^{2}, 30 \mathrm{~min}\right)$ samples tested at $20^{\circ} \mathrm{C}$. EPT indicates electric pulse treatment. b) The reduction in cross section area of as-received, brittle and electric-pulse-treated samples after tensile testing. (Online version in color.) 
Fig. 5(b). The reduction in the cross-sectional area indicates that the plasticity was restored after electropulsing treatment. This result, along with that in Fig. 3, shows that the brittle sample has more dislocation defects. Owing to the increase in dislocation density, it was difficult for dislocations to slip; thus, hardening and strengthening occurred. After the electric pulse treatment, the dislocation defects were reduced. The elongation was improved to $16.0 \%$, and the yield stress and tensile stress decreased slightly, indicating that the strength and plasticity were restored under the electric field.

Toughness is one of the most important mechanical properties of RPV steel. After irradiation, RPV steel shows significant embrittlement. ${ }^{38)}$ The Charpy V-notch impact test was performed to determine the impact toughness of the samples from $-150^{\circ} \mathrm{C}$ to $25^{\circ} \mathrm{C}$. In the Charpy impact absorbed energy curve, the upper shelf energy indicates the toughness at high temperature. As shown in Fig. 6, the upper shelf energies of the as-received, brittle, and electric-pulsetreated samples are 79.4, 60.4, and $66.0 \mathrm{~J}$, respectively. This result shows that the brittle sample had lower impact resistance at room temperature. After electropulsing, the upper shelf energy was higher. According to ASTM A370, the DBTTs of the as-received, brittle, and treated samples

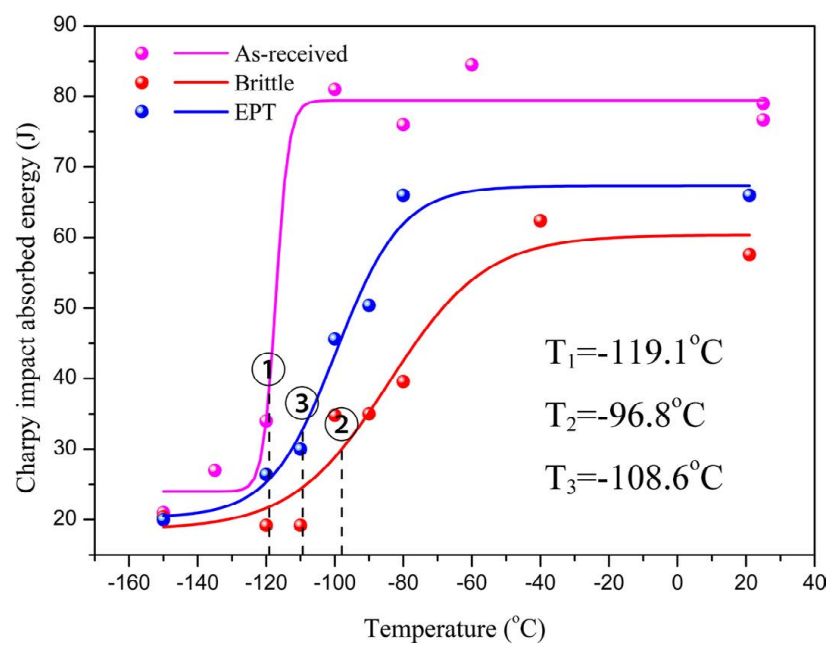

Fig. 6. Charpy impact curves of as-received, brittle, and electricpulse-treated $\left(500 \mathrm{~Hz}, 20 \mu \mathrm{s}, 4 \mathrm{~A} / \mathrm{mm}^{2}, 30 \mathrm{~min}\right)$ samples from $25^{\circ} \mathrm{C}$ to $-150^{\circ} \mathrm{C}$. EPT indicates electric pulse treatment. (Online version in color.) were $-119.1^{\circ} \mathrm{C},-96.8^{\circ} \mathrm{C}$ and $-108.6^{\circ} \mathrm{C}$, respectively. The DBTT of the brittle sample was $22.3^{\circ} \mathrm{C}$ higher than that of the as-received sample, indicating that the toughness of the brittle sample had decreased. The electric pulse treatment reduced the DBTT by $11.8^{\circ} \mathrm{C}$. Considering the decrease in dislocation density under the electric field, it is clear that the electric pulse treatment reduced the dislocation defects and restored the toughness of the brittle sample. The recovery rate of the toughness can be calculated as $11.8 / 22.3 \times$ $100 \%=52.9 \%$.

In agreement with the dislocation density calculated by the MWH method, the yield stress and DBTT of the brittle sample increased dramatically because the dislocation density was three times higher than that in the as-received sample. Moreover, electric pulse treatment for $30 \mathrm{~min}$ reduced the dislocations in the brittle sample by almost half and restored the strength and impact toughness. According to the experimental results, a reduction in the dislocation defects and an improvement in the toughness of large pressure vessels under an electric field can be expected, although there are many critical issues such as the pulse application method and the required power of the electrical source owing to the very large size of RPVs.

Figures 3(d), 3(e), and 3(f) show that the brittle sample has a higher dislocation density and some carbides. As shown in Fig. 7(a), $\mathrm{Fe}_{3} \mathrm{C}$ precipitates pin the dislocations and limit their movement. Therefore, the brittle sample has higher strength and lower toughness. Electric pulse treatment can reduce the pinning effect of $\mathrm{Fe}_{3} \mathrm{C}$ on the dislocations and promote dislocation movement, as shown in Fig. 7(b). There are two main reasons: (1) the electron wind force accelerates dislocation slipping and increases the probability of dislocation annihilation; (2) electric pulse treatment decreases the activation energy of dislocation movement and thus promotes dislocation depinning.

A pulsed electric current can reduce the dislocation defects and change the dislocation structure. Conrad ${ }^{39-41)}$ quantized the interaction between electrons and dislocations and obtained the following function describing the electron wind force:

$$
F_{e w}=\left(\rho_{d} / N_{d}\right) \cdot e \cdot n_{e} j
$$

where $F_{\text {ew }}$ is the force per unit dislocation length exerted by electrons, $\left(\rho_{d} / N_{d}\right)$ is the specific dislocation resistivity, $e$ is
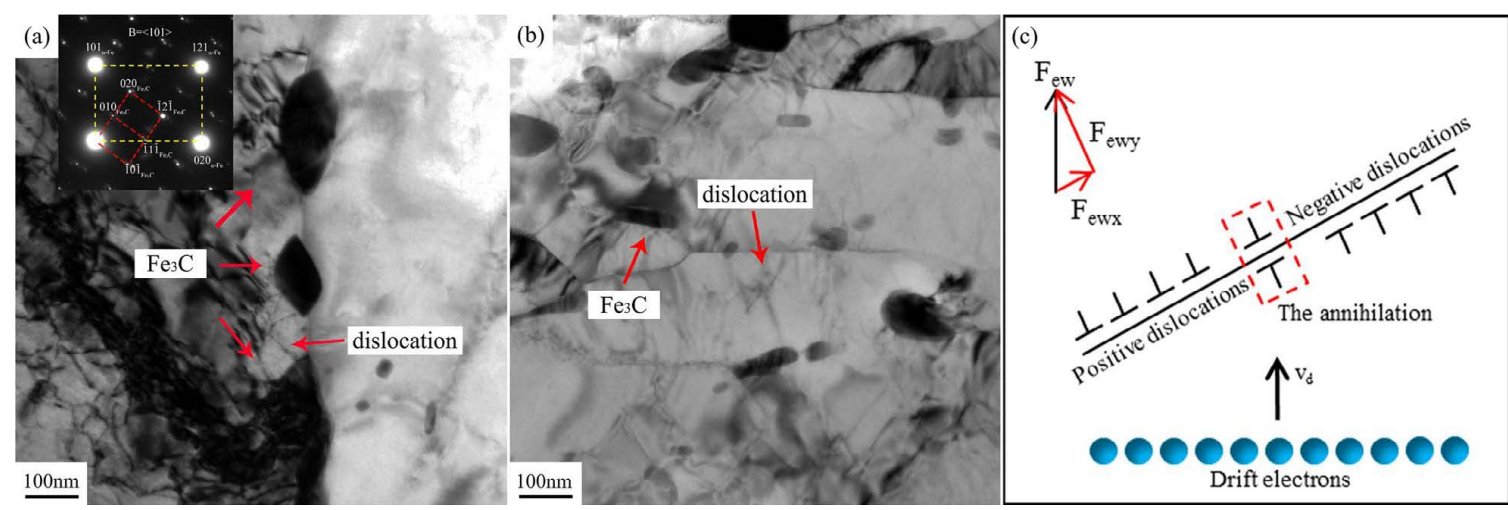

Fig. 7. a) Pinning of dislocations by $\mathrm{Fe}_{3} \mathrm{C}$ in the brittle sample, b) depinning of dislocations by electric pulse treatment $\left(500 \mathrm{~Hz}, 20 \mu \mathrm{s}, 4 \mathrm{~A} / \mathrm{mm}^{2}, 30 \mathrm{~min}\right)$, c) schematic of the effect of the electron wind force on the dislocations. (Online version in color.) 
the electron charge, $n_{\mathrm{e}}$ is the electron concentration, and $j$ is the current density.

Using quantum mechanics, Conrad derived the function

$$
F_{e w}=\alpha b p_{f} n_{e}\left(v_{e}-v_{d}\right)
$$

where $\alpha$ is $0.25-1.0 ; b$ is the Burgers vector, $p_{\mathrm{f}}$ is the Fermi momentum, $v_{\mathrm{e}}$ is the electron drift velocity, and $v_{\mathrm{d}}$ is the dislocation velocity. The electron wind force $F_{\text {ew }}$ promotes dislocation movement when the drift electrons move faster than the dislocations. Positive and negative dislocations are subjected to forces of the same magnitude and opposite directions. As shown in Fig. 7(c), because the force is applied in opposite directions, the positive and negative dislocations in the same slip plane move in opposite directions. The electron wind force causes the dislocations to approach and annihilate each other, reducing the dislocation density. Further, the electron wind force perpendicular to the slip plane also causes the dislocations to climb and enhances the toughness of the material.

According to Sprecher's investigations, ${ }^{42)}$ the activation energy of dislocation movement is given by Eq. (4):

$$
\Delta G=\Delta H^{*}-T \Delta S^{*}
$$

where $\Delta H\left(\sigma^{*}\right)=\Delta H^{*}-v^{*} \sigma^{*} ; \sigma^{*}$ is the effective stress required to activate the dislocations and will change under an electric field as shown in Eq. (5):

$$
\sigma^{*}(t)=\sigma_{0}^{*}-E\left(\Delta \varepsilon_{P}+\Delta \varepsilon_{T}+\Delta \varepsilon_{N}\right)+\mu_{m} J^{2} a^{2} / 4+\sigma_{e d} \cdots
$$

where $E$ is the Young's module of the sample, $\Delta \varepsilon_{p}$ is the microplastic strain of the material, $\Delta \varepsilon_{T}=\alpha_{L} \Delta T$ is the strain due to thermal expansion resulting from an increase in temperature, $\Delta \varepsilon_{N}=v_{p} \mu_{m} J^{2} a^{2} / 2 E$ is the elastic strain produced by the pinch effect, and $\mu_{m} J^{2} a^{2} / 4$ is the increase in the Tresca stress due to the radial stress component produced by the pinch effect. $\sigma_{e d}$ is the electron dislocation interaction stress; because of the existence of $\sigma_{e d}$, the effective stress affecting dislocations increases, which decreases the activation enthalpy. Furthermore, the Gibbs free energy of activation decreases as described by Eq. (4), and thus the dislocations slip more easily.

In addition, according to Ohm's law, ${ }^{43)}$ the voltage of the material is given by Eq. (6):

$$
V=R I
$$

where $R=\rho \frac{L}{S}$ is the resistance of the material, and $\rho$ is the resistivity. When the current density, $J=\frac{I}{S}$, and electric field intensity, $E^{*}=\frac{V}{L}$, are substituted into Eq. (6), the current density is given by

$$
\vec{J}=\frac{1}{\rho} \overrightarrow{E^{*}}=\sigma^{*} \overrightarrow{E^{*}}
$$

where $\sigma^{*}=\frac{1}{\rho}$ is the conductivity of the material. Furthermore, the current can be regarded as directional movement of the electrons. The current $I$ is written as

$$
I=\frac{\left[v_{e} \cdot \Delta t \cdot S\right] n(-q)}{\Delta t}=(-q) n S v_{e}
$$

$n$ is the number of electrons, and $q$ is the electron charge. Then the current density is $J=n q v_{e}$. The electron drift velocity is

$$
v_{e}=\mu^{*} E^{*}
$$

where $\mu^{*}$ is the electron migration rate. By combining Eqs. (7)-(9), the conductivity of the material can be written as

$$
\sigma^{*}=n q \mu^{*}
$$

It is known that the free electrons cannot be constantly accelerated under an electric field in a material. Owing to the effect of electron scatter, the electrons will move at a stable velocity. The number of electrons that are not scattered, $N(t)=N_{0} \exp (-P t) \cdot N_{0}$ is the number of electrons at $t=0$, and $P$ is the scatter rate of electrons per unit time. Then the electron relaxation time is $\tau^{*}=\frac{1}{N_{0}} \int_{0}^{\infty} t \cdot P \cdot N_{0} \exp (-P t) d t=\frac{1}{P}$. When these expressions are substituted for $N(t)$, the number of unscattered electrons is given by

$$
N(t)=N_{0} \exp \left(-t / \tau^{*}\right)
$$

Assuming that the electrons have an initial velocity $v_{\mathrm{e} 0}$ at $t=0$, at a later time $t$, the velocity of electrons under the electric field is given by

$$
v_{e}(t)=v_{e 0}-\frac{q E^{*}}{m_{n}^{*}} t
$$

where $m_{n}^{*}$ is the conductivity effective mass of the electron. The velocity of all the electrons $\left\langle v_{\mathrm{e}}(t)\right\rangle$ is summed, considering that at $t=0$, the initial velocities have different directions, and thus the sum of the initial velocities of the electrons is statistically zero, and the average velocity of the electron $v_{e}$ is obtained:

$$
\begin{gathered}
\overline{v_{e}}=\frac{1}{N_{0}} \int_{0}^{\infty}\left(-\frac{q E^{*}}{m_{n}^{*}} t\right) \frac{1}{\tau^{*}} N_{0} \exp \left(-\frac{t}{\tau^{*}} d t\right)=-\frac{q E^{*}}{m_{n}^{*}} \tau^{*} \ldots \\
\mu=\frac{\overline{v_{e}}}{E}=\frac{q \tau^{*}}{m_{n}^{*}} \ldots \ldots \ldots \ldots \ldots \ldots \ldots \ldots \ldots \ldots \ldots \ldots \ldots
\end{gathered}
$$

The average electron velocity and the migration rate are clearly proportional to the relaxation time.

The interfacial dislocation scattering can be handled in the same way as the Coulomb scattering. ${ }^{44)}$ Considering that the dislocation defects and the lattice both scatter electrons because of lattice vibration, the effect of scattering by the dislocation defects is stronger than that by the grain lattice owing to the occurrence of dislocation scattering. Then the relaxation time of materials with dislocation defects is shorter than that of materials without dislocations. As shown in Eq. (14), the migration rate of electrons is lower at the dislocations. According to Eq. (10), the conductivity of the dislocations is lower, and thus the resistivity of the dislocations is higher. In light of Joule's law, the temperature of the dislocation defects is higher than that of the regular lattice. Therefore, the activation energy of dislocation movement is decreased, and the dislocations slip easily for other reasons in addition to the electron wind force.

To prove the theory above, the resistivity of the dislocation defects should be determined. However, it is difficult to measure the resistivity of the dislocations directly. Accord- 


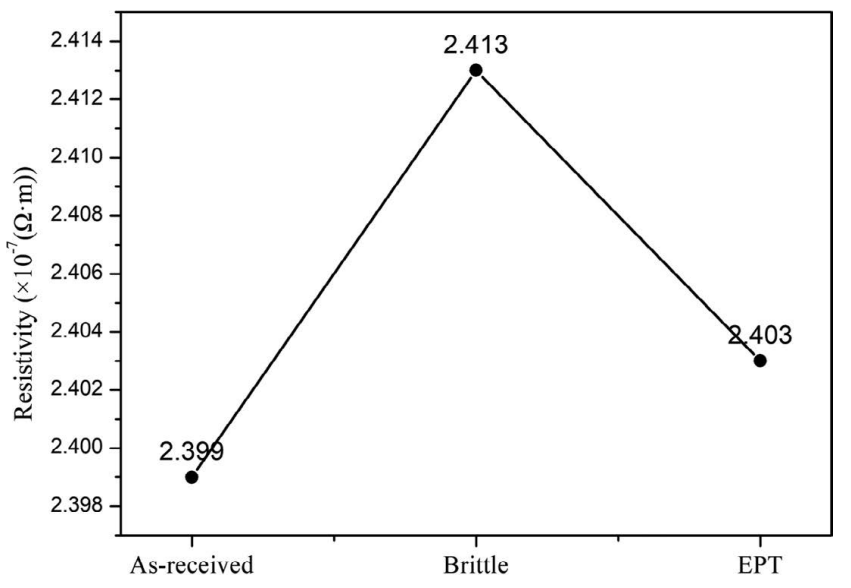

Fig. 8. Comparison of electrical resistivities of samples. EPT indicates electric pulse treatment.

ing to Matthiessen's rule, the total resistivity of a material with high dislocation density is bigger in the case of the same other conditions, and the total resistivity can be calculated as ${ }^{45)}$

$$
\rho_{\text {total }}=\rho_{\text {pristine }}+\rho_{\text {phonons }}+\rho_{\text {defects }}
$$

As shown in Fig. 8, the brittle sample had higher resistivity than the as-received sample because it had more dislocation defects. After electric pulse treatment, the resistivity dropped dramatically, demonstrating that the electric pulse treatment reduced the dislocation defects.

In the pulsed current field, owing to the electron wind force and dislocation scattering, the activation energy of the dislocations decreased overall, improving the dislocation mobility. As they move, positive and negative dislocations may approach and annihilate each other, decreasing the dislocation density.

\section{Conclusion}

In summary, the effects of electropulsing on the dislocation defects and mechanical properties of A508-3 steel were investigated. The results showed that the dislocation density decreased by $45 \%$ in the brittle sample after $30 \mathrm{~min}$ of electric pulse treatment, and the dislocations became discrete, as they were in the undamaged sample. The strength was decreased and the plasticity and toughness were improved as a result of the reduction in dislocations. According to a calculation, the recovery rate of the DBTT was higher than $50 \%$. Further, the interaction between the pulse current and dislocations was explained in terms of the electron wind force and the activation energy theory. This research suggests a new method for quick, energy-efficient in situ repair of brittle RPV steel (A508-3).

\section{Acknowledgements}

The work was financially supported by National Natural Science Foundation of China (51874023, 51601011, U1860206), Fundamental Research Funds for the Central Universities (FRF-TP-18-003B1), Recruitment Program of Global Experts.

\section{REFERENCES}

1) G. I. Taylor: Proc. R. Soc. A, 145 (1934), 362

K. Lu: Science, 328 (2010), 319

3) X. Huang, N. Hansen and N. Tsuji: Science, 312 (2006), 249

4) M. Wang, B. B. He and M. X. Huang: J. Mater. Sci. Technol., 35 (2019), 394.

5) Y. Lin, W. Yang, Z. F. Tong, C. Y. Zhang and G. S. Ning: Eng. Failure Anal., 82 (2017), 733.

6) K. Fujii, K. Fukuya, R. Kasada, A. Kimura and T. Ohkubo: J. Nucl. Mater., 458 (2015), 281.

7) M. K. Miller and K. F. Russell: J. Nucl. Mater., 371 (2007), 145

8) B. Marini, X. Averty, P. Wident, P. Forget and F. Barcelo: J. Nucl. Mater., 465 (2015), 20.

9) J. E. Pawel, A. F. Rowcliffe, D. J. Alexander, M. L. Grossbeck and K. Shiba: J. Nucl. Mater., 233 (1996), 202.

10) R. G. Lott, T. R. Mager, R. P. Shogan and S. E. Yanichko: Radiation Embrittlement of Nuclear Reactor Pressure Vessel Steels: An International Review (2nd Vol.), ASTM Special Technical Publication, Philadelphia, PA, (1986), 242. https://doi.org/10.1520/STP23039S

11) P. Auger, P. Pareige, S. Welzel and J. C. Van Duysen: J. Nucl. Mater., 280 (2000), 331.

12) A. Ulbricht, F. Bergner, J. Bohmert, M. Valo, M. H. Mathon and A. Heinemann: Philos. Mag., 87 (2007), 1855.

13) M. K. Miller, R. K. Nanstad, M. A. Sokolov and K. F. Russell: J. Nucl. Mater., 351 (2006), 216.

14) U. Potapovs, J. R. Hawthorne and C. Z. Serpan, Jr.: Nucl. Appl., 5 (1968), 389.

15) R. Ahlstrand, K. Törrönen, M. Valo and B. Bärs: Radiation Embrittlement of Nuclear Reactor Pressure Vessel Steels: An International Review (2nd Vol.), ASTM Special Technical Publication, Philadelphia, PA, (1986), 55. https://doi.org/10.1520/STP23028S

16) J. W. Yan, W. Li, H. T. Liu and Y. Shen: Scr. Mater., 167 (2019), 86.

17) S. Q. Xiang and X. F. Zhang: Mater. Sci. Eng. A, 761 (2019), 138026.

18) H. Conrad, Z. Guo and A. F. Sprecher: Scr. Metall., 23 (1989), 821.

19) Z. Y. Zhao, G. F. Wang, Y. L. Zhang, Y. Q. Wang and H. L. Hou: J. Alloys Compd., 786 (2019), 733.

20) H. S. Maharana, B. Bishoyi and A. Basu: J. Alloy. Compd., 787 (2019), 483.

21) S. Y. Xie, R. D. Li, L. J. Tang and T. C. Yuan: Mater. Lett., 253 (2019), 381

22) S. H. Deng, T. C. Yuan, R. D. Li, M. Zhang, S. Xie, M. Wang, L. Li, J. Yuan and Q. Weng: Int. J. Refract. Met. Hard Mater., 75 (2018), 184.

23) M. J. Kim, K. Lee, K. H. Oh, I. S. Choi, H. H. Yu, S. T. Hong and H. N. Han: Scr. Mater., 75 (2014), 58.

24) Y. P. Tang, A. Hosoi, Y. Morita and Y. Ju: Int. J. Fatigue, 56 (2013), 69.

25) K. Liu, X. H. Dong and W. Shi: Trans. Nonferr. Met. Soc. China, 29 (2019), 735.

26) W. Li, Y. Shen, H. T. Liu, Y. Wang, W. J. Zhu and C. Y. Xie: $J$. Mater. Res., 31 (2016), 1193.

27) R. Hahn, M. Bartosik, M. Arndt, P. Polcik and P. H. Mayrhofer: Int. J. Refract. Met. Hard Mater., 71 (2018), 352.

28) Z. Q. Zhang, H. Y. Jing, L. Y. Xu, Y. D. Han, L. Zhao, X. Q. Lv and J. Y. Zhang: J. Manuf. Process., 31 (2018), 568.

29) H. B. Long, H. Wei, Y. N. Liu, S. C. Mao, J. X. Zhang, S. S. Xiang, Y. H. Chen, W. M. Gui, Q. Li, Z. Zhang and X. D. Han: Acta Mater., 120 (2016), 95.

30) Y. L. Wei, A. Godfrey, W. Liu, Q. Liu, X. Huang, N. Hansen and G. Winther: Scr. Mater., 65 (2011), 355.

31) B. L. Averbach and B. E. Warren: J. Appl. Phys., 20 (1949), 885.

32) T. Ungár: Scr. Mater., 51 (2004), 777.

33 T. Ungár, I. Dragomir, Á. Révész and A. Borbély: J. Appl. Crystallogr., 32 (1999), 992.

34) T. Ungár, S. Ott, P. G. Sanders, A. Borbély and J. R. Weertman: Acta Mater., 46 (1998), 3693.

35) T. Ungár and A. Borbély: Appl. Phys. Lett., 69 (1996), 3173.

36) V. Stolyarov: Acta Metall. Sin. (Engl. Lett.), 31 (2018), 1305.

37) R. Chaouadi and R. Gérard: J. Nucl. Mater., 418 (2011), 137.

38) M. K. Miller, A. A. Chernobaeva, Y. I. Shtrombakh, K. F. Russell, R. K. Nanstad, D. Y. Erak and O. O. Zabusov: J. Nucl. Mater., 385 (2009), 615

39) H. Conrad: Mater. Sci. Eng. A, 287 (2000), 276

40) K. Okazaki, M. Kagawa and H. Conrad: Scr. Metall., 13 (1979), 277.

41) H. Conrad: Mater. Sci. Eng. A, 322 (2002), 100.

42) A. F. Sprecher, S. L. Mannan and H. Conrad: Acta Metall., 34 (1986), 1145.

43) G. S. Ohm: J. Chemie and Physik (Schweigger's Journal), 46 (1826), 137.

44) B. Liu, Y. W. Lu, Y. Huang, G. P. Liu, Q. S. Zhu and Z. G. Wang: Phys. Lett. A, 376 (2012), 1067.

45) H. Akhoondali, A. Y. Goharrizi and M. J. Sharifi: Physica. E, 74 (2015), 168 